\title{
ANALISIS PEMAHAMAN DAN PELANGGARAN EARLY WARNING SYSTEM (EWS) TERHADAP ANGKA KECELAKAAN DI PERLINTASAN SEBIDANG DENGAN METODE CHI-SQUARE
}

\author{
${ }^{1}$ Ary Putra Iswanto, Email : aryputra@ppi.ac.id, \\ ${ }^{2}$ Nanda Ahda Imron, Email : nanda@ppi.ac.id, \\ ${ }^{3}$ Sapto Priyanto, Email : sapto@ppi.ac.id, \\ ${ }^{1), 2), 3)}$ Politeknik Perkeretaapian Indonesia Madiun, Indonesia
}

\begin{abstract}
ABSTRAK
Penelitian ini bertujuan untuk mengetahui hubungan pemahaman EWS dan jumlah pelanggaran dengan angka kecelakaan di perlintasan sebidang yang terjadi di perlintasan sebidang KM 287+8.Jenis penelitian ini merupakan studi kasus yang merupakan penelitian terhadap subjek dan objek yang telah ditentukan sebelumnya. Jumlah responden yang diteliti dalam penelitian ini adalah sebanyak 360 responden, pengamatan dilakukan terhadap jumlah pelanggaran dan angka kecelakaan yang dilakukan selama 20 hari pengamatan dan pemahaman responden, sementara metode analisa yang digunakan adalah metode korelasional dengan menggunakan tabulasi silang (crosstab) dan pearson chisqure. Hasil penelitian menunjukan bahwa pemahaman EWS memiliki hubungan yang sangat lemah dan searah dengan angka kecelakaan di perlintasan sebidang, hal ini menunjukan bahwa semakin tinggi tingkat pemahaman EWS seorang pengendara, maka akan dapat menekan atau menimalisir jumlah kecelakaan yang terjadi di perlintasan sebidang yang memiliki EWS dan jumlah pelanggaran memiliki hubungan yang sedang dan searah dengan angka kecelakaan di perlintasan sebidang, hal ini menunjukan bahwa semakin tinggi jumlah pelanggaran, maka akan semakin meningkatkan jumlah kecelakaan.
\end{abstract}

Kata Kunci: Pemahaman EWS, Jumlah Pelanggaran, Angka Kecelakaan.

\section{ABSTRACT}

The research aims to determine the understanding of EWS and the number of violations with the number of accidents in the crossing of a field that occurred at the crossing of KM $287+8$. This type of research is a case study that is research on pre-defined subjects and objects. The number of respondents examined in this study was 360 respondents, observations were conducted against the number of violations and the number of accidents carried out during 20 days of observation and understanding of respondents, while the method of analysis used was correlational method using cross tabulation (crosstab) and pearson chisqure. The results show that understanding EWS has a very weak relationship and is in line with the accident rate at the level crossing, this shows that the higher the level of understanding of a motorist's EWS, it will be able to suppress or minimize the number of accidents that occur at level crossings that have EWS and the number violations have a moderate relationship with the number of accidents at a level crossing, this shows that the higher the number of violations, the more the number of accidents that occur.

Keywords: EWS Understanding, Number of Violations, Number of Accidents

\section{PENDAHULUAN}

Perkeretaapian merupakan transportasi

yang khusus antara lain dapat mengangkut orang secara masal, hemat energi, menghemat ruang, pencemaran udara minim, dan tingkat keamanan 
tinggi. Namun demikian penyelenggara sarana perkeretaapian tetap wajib mengutamakan keselamatan orang berdasarkan UU No. 23 tahun 2007 tentang perkeretaapian pada pasal 133.

Perjalanan kereta api tidak terlepas dari adanya perlintasan sebidang antara rel kereta api dan jalan. Perlintasan sebidang atau perlintasan kereta api adalah perpotongan sebidang antara jalur kereta api dengan jalan. Perlintasan sebidang terbagi menjadi 2 jenis yaitu perlintasan resmi dijaga maupun tidak dijaga dan perlintasan sebidang tidak resmi atau bersifat liar.

Di Jawa Barat tercatat terdapat 1400 perlintasan sebidang dengan rincian 880 tidak berpintu, 170 tanpa pintu yang dilengkapi dengan Early Warning System (EWS), 350 sudah berpintu, dengan kecelakaan tertinggi terjadi di perlintasan sebidang resmi tidak dijaga (Dinas Perhubungan Provinsi Jawa Barat, 2013). Menurut (Omy, 2019) penyebab kecelakaan dipengaruhi oleh beberapa faktor yaitu pengguna jalan tidak disiplin dalam mematuhi peraturan berlalu lintas dan minimnya fasilitas rambu-rambu di perlintasan sebidang. Perlintasan sebidang yang tidak memenuhi standar peraturan yang berlaku masih banyak ditemukan di Daerah Operasi 2 Bandung. Salah satunya berada di desa benteng Kecamatan Ciamis Kabupaten Ciamis Provinsi Jawa Barat.

Menurut (Badan Pusat Statistik, 2017) penduduk di kota Ciamis berjumlah 100.857 juta jiwa sehingga akan mempengaruhi lalu lintas yang semakin padat dan akan menimbulkan potensi kecelakaan di perlintasan sebidang. Menurut (Lewin, 1982) faktor manusia berkontribusi terhadap kecelakaan lalu lintas sampai 90\%. Juneman, 2010) mengatakan bahwa tidak semua kecelakaan disebabkan oleh human error.

Kecelakaan yang terjadi di perlintasan sebidang berpalang pintu, dengan EWS, maupun tanpa EWS selalu mengalami kenaikan dari tahun ke tahun. Menurut (Satri, 2006) EWS merupakan serangkaian sistem atau alat/yang berfungsi mengumpulkan informasi yang berguna untuk dijadikan sistem pengawasan. Kecelakaan memiliki tiga faktor penyebab utama berdasarkan Haddon's Matrix yakni faktor manusia, kendaraan, dan lingkungan yang terbagi dalam tiga tahap pra, saat, dan pasca-kecelakaan. Faktor dalam tahap pra-kecelakaan guna mencegah terjadinya kecelakaan, faktor dalam tahap saat kecelakaan guna pencegahan cedera, dan faktor dalam tahap pasca-kecelakaan guna mempertahankan hidup (Mohan dkk., 2006).

Faktor manusia dan teknologi menjadi sorotan dalam banyak kasus kecelakaan kereta api. Ketersediaan teknologi yang menyebabkan kecelakaan kereta api adalah rusaknya sarana ataupun prasarana yang meliputi sistem komunikasi, sistem persinyalan, kerusakan pada petunjuk kecepatan lokomotif, tidak berfungsinya sistem pengereman dengan maksimal, kondisi rel yang tidak baik (kondisi ballast, bantalan, dan alat penambalan yang tidak baik), terjadi genjotan track, keadaan wesel rel yang tidak baik, dan kehausan pada kop rel merupakan beberapa masalah yang sering muncul. Jaringan sensor perlindungan keselamatan kereta api adalah salah satu peralatan modern yang secara strategis menempatkan sekelompok sensor khususnya di dalam kendaraan yang dapat merekam berbagai parameter penting dan kode kesalahan terhitung waktu nyata yang cepat untuk melatih pengemudi atau operator (Guoqiang Cai, 202).

Pada tiga tahun pertama EWS berhasil menekan angka kecelakaan di perlintasan sebidang. Namun empat tahun berikutnya angka kecelakaan di perlintasan yang di lengkapi EWS mengalami naik turun. Pada tahun 2018 kecelakaan kereta api di perlintasan mengalami kenaikan angka kecelakaan dibandingkan dengan perlintasan tanpa EWS. Berdasarkan latar belakang masalah tersebut, maka peneliti tertarik untuk melakukan penelitian lebih lanjut mengenai "Analisis Pemahaman dan Pelanggaran Early Warning System (EWS) terhadap Angka Kecelakaan di Perlintasan Sebidang dengan Metode Chi Square". 


\section{METODE PENELITIAN}

\section{Diagram Alir}

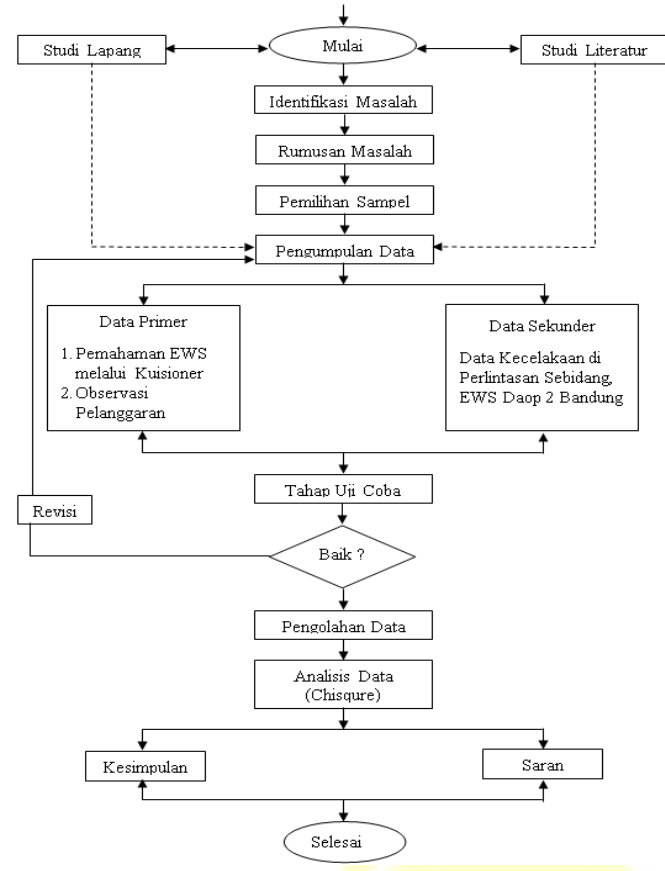

Gambar 1. Diagram Alir

\subsection{Metode Pengumpulan Data}

Metode pengumpulan data pada penelitian ini adalah data primer dan sekunder. Data primer diperoleh melalui penyebaran kuisioner dengan skala likert terhadap responden yaitu pengguna jalan raya yang menggunakan kendaraan bermotor roda 2 dan roda 4 . Selain dengan kuesioner, data primer juga diperoleh melalui obsevasi lapangan untuk mengetahui pengguna jalan yang melanggar ketika EWS bekerja saat kereta api melintas di perlintasan sebidang dalam satu hari selama satu bulan. Data sekunder diperoleh saat melaksanakan Praktik Kerja Lapangan (PKL) berupa data Kecelakaan di Perlintasan sebidang di Daerah Operasi 2 bandung.

Observasi dilakukan pada jam hari kerja berdasarkan (Wardana, D.H, 2004) waktu jam puncak terjadi pada jam kerja (06.10 s/d 07.10) dan pulang kerja (15.00 s/d 16.00). Berdasarkan hasil observasi lapangan populasi yang diperoleh 150 kendaraan saat kereta melintasi tempat penelitian selama satu hari. Sedangkan sampel yang diambil menggunakan teknik simple random sampling dengan menggunakan rumus Slovin pada tingkat presentasi ketelitian 5\% dan diperoleh sampel berjumlah 360 sampel/bulan.

Variabel penelitian terdiri dari variabel bebas (independent) dan variabel terikat (dependent). Variabel Bebas pada penelitian ini adalah pemahaman EWS kepada pengguna jalan raya dan pelanggaran dalam melaksanakan fungsi kerja EWS. Sedangkan variabel terikat yang digunakan adalah angka kecelakaan di perlintasan sebidang yang dilengkapi EWS.

\subsection{Metode Analisis Data}

\section{Analisis Deskriptif}

Analisis deskriptif dilakukan untuk melihat gambaran karakteristik responden dilihat dari sisi jenis kelamin dan usia responden dengan membuat tabel distribusi frekuensi berdasarkan karakteristiknya dan untuk melihat gambaran variabel penelitian dengan melihat nilai rata-rata skor jawaban responden pada setiap pertanyaan kuesioner.

\section{Validitas dan Reliabilitas Instrumen}

Uji validitas dan reliabilitas instrumen dilakukan terhadap 30 responden. Uji validitas yang digunakan adalah uji validitas dengan corrected item-total correlation dengan bantuan program SPSS 25, sedangkan uji reliabilitas menggunakan uji reliabilitas Cronbach's Alpha yang dilakukan dengan melihat nilai Cronbach's Alpha masing-masing instrumen.

Dalam (Ghozali, 2016), pengujian validitas dengan menggunakan corrected item - total correlation dilakukan dengan membandingkan nilai $\mathrm{r}$ hitung dan $\mathrm{r}$ tabel pada derajat bebas sebesar $\mathrm{n}-2$ pada taraf signifikansi $5 \%$. Apabila nilai $r$ hitung $>r$ tabel dan nilai positif maka butir atau pertanyaan atau indikator tersebut dinyatakan valid. Sedangkan jika $r$ hitung $<r$ tabel maka butir atau pertanyaan atau indikator tersebut dinyatakan tidak valid.Uji reliabilitas cronbachs alpha menyatakan reliabel jika nilai cronbachs alpha> 0,6 .

\section{Analisis Pearson Chi-Square}

Menurut Andi Supangat uji chi square merupakan uji hipotesis tentang asosiasi atau korelasi antara frekuensi observasi dengan frekuensi harapan yang didasarkan pada hipotesis tertentu pada setiap penelitian. Dasar pengambilan 
keputusan yaitu jika nilai Asymp. Sig (2-sided) > 0.05, maka Ho diterima dan Ha ditolak, artinya tidak terdapat hubungan yang signifikan. Sedangkan jika nilai Asymp. Sig (2-sided) <0.05, maka Ho ditolak dan Ha diterima, artinya terdapat hubungan yang signifikan.Untuk melihat hubungan antar dua variabel digunakan koefisien kontingensi. Uji korelasi ini mempunyai kaitan erat dengan chi-square yang dipergunakan untuk menguji komparatif sampel independen karena dalam koefisien kontingensi digunakan rumus chisquare (Sugiyono, 2016:39). Berikut ini tingkat keeratan Koefesien Korelasi kontingensi.

Tabel 1. Kriteria Koefisien Korelasi

\begin{tabular}{cc}
\hline Interval & Kriteria \\
\hline $\mathbf{0 . 0 0 0}-\mathbf{0 . 1 9 9}$ & Sangat Lemah \\
\hline $\mathbf{0 . 2 0 0}-\mathbf{0 . 3 9 9}$ & Lemah \\
\hline $\mathbf{0 . 4 0 0}-\mathbf{0 . 5 9 9}$ & Sedang \\
\hline $\mathbf{0 . 6 0 0}-\mathbf{0 . 7 9 9}$ & Kuat \\
\hline $\mathbf{0 . 8 0 0}-\mathbf{1 . 0 0}$ & Sangat Kuat \\
\hline
\end{tabular}

\section{HASIL DAN PEMBAHASAN}

\subsection{Gambaran Profil Responden}

Penelitian ini melibatkan 360 responden dan pengamatan terhadap jumlah pelanggaran dan angka kecelakaan selama 20 hari. Berikut ini adalah hasil analisis deskriptif karakteristik responden berdasarkan jenis kelamin.

Tabel 2. Jenis Kelamin

\begin{tabular}{ccc}
\hline $\begin{array}{c}\text { Jenis } \\
\text { Kelamin }\end{array}$ & $\begin{array}{c}\text { Frekuensi } \\
\text { (f) }\end{array}$ & Persentase (\%) \\
\hline Laki-laki & 200 & 55.6 \\
\hline Perempuan & 160 & 44.4 \\
\hline Total & 360 & 100 \\
\hline
\end{tabular}

Berdasarkan hasil analisis di atas menunjukkan bahwa dari 360 responden yang diteliti dalam penelitian ini, sebagian besar responden berjenis kelamin laki-laki (55.6\%), sisanya sebanyak $(44.4 \%)$ responden berjenis kelamin perempuan.

Tabel 3. Usia Responden

\begin{tabular}{ccc}
\hline Usia & Frekuensi (f) & Persentase $(\%)$ \\
\hline$<\mathbf{2 5}$ tahun & 128 & 35.6 \\
\hline $\mathbf{2 5}-\mathbf{3 5}$ tahun & 99 & 27.5 \\
\hline $\mathbf{3 5} \mathbf{- 4 5}$ tahun & 75 & 20.8 \\
\hline$>\mathbf{4 5}$ tahun & 58 & 16.1 \\
\hline Total & 360 & 100
\end{tabular}

Sedangkan berdasarkan usia, dari 360 responden yang diteliti, sebagian besar responden berusia < 25 tahun (35.6\%). Hal ini menunjukkan bahwa sebagian besar responden dalam penelitian ini masih berusia produktif.

\subsection{Gambaran Variabel Penelitian}

Tingkat pemahaman EWS pengguna jalan di perlintasan sebidang diukur dengan 8 pertanyaan. Hasil analisis menunjukkan bahwa tingkat pemahaman pengguna jalan terhadap EWS cenderung baik. Sedangkan jenis pelanggaran yang paling sering terjadi selama penelitian ini adalah pengguna jalan tidak berhenti saat lampu merah menyala dan sirine berbunyi serta melewati batas sinyal EWS. Namun demikian, persentase jumlah pelanggar yang melewati batas sinyal EWS hanya sebesar 20\%. Sedangkan angka kecelakaan yang dihitung selama 20 hari dari data sekunder. Berikut ini hasil pengamatan pelanggaran serta angka kecelakaan selama 20 hari.

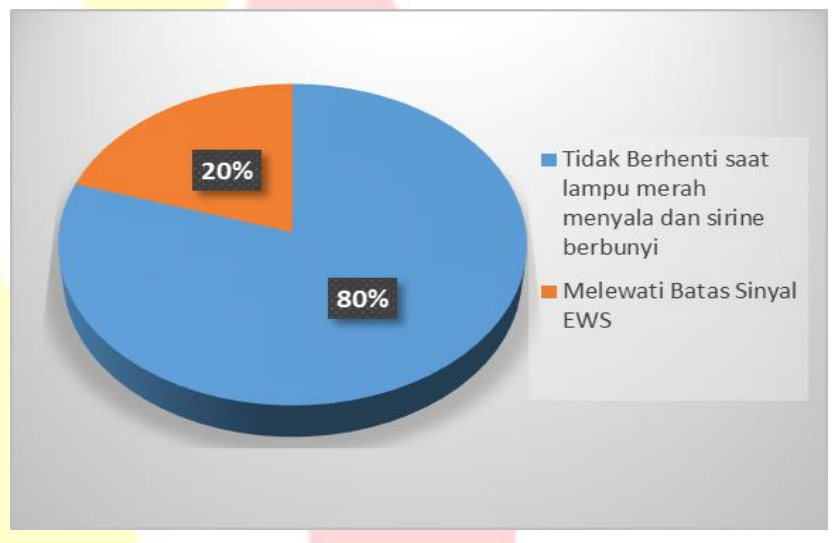

Sumber : Hasil Olah Data

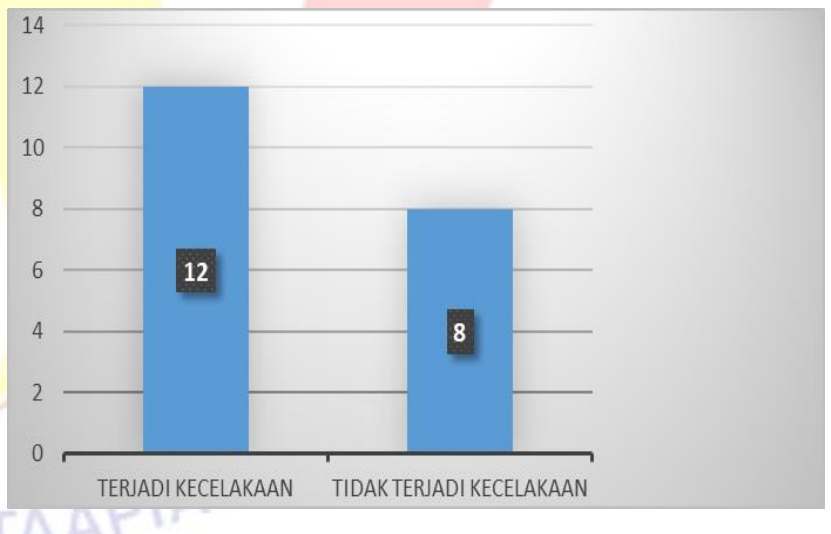

Sumber : Hasil Olah Data

Berdasarkan hasil menunjukan bahwa terjadi kecelakaan sebanyak 12 kali dan 8 kali tidak 
tejadi kecelakaan. Hal ini menunjukkan angka kecelakaan yang cukup tinggi. Berdasarkan hasil observasi, kasus yang paling banyak terjadi adalah kereta ditempar oleh orang yang tetap melewati perlintasan meskipun lampu telah menyala dan sirine telah berbunyi.

\subsection{Validitas dan Reliabilitas Instrumen}

Berikut ini adalah hasil uji validitas dan reliabilitas instrumen penelitian yang dilakukan.

Tabel 4. Hasil Uji Validitas dan Reliabilitas

\begin{tabular}{ccc}
\hline Pertanyaan & $\begin{array}{c}\text { Pearson } \\
\text { Correlation }\end{array}$ & Sig.(2-1 \\
\hline P1 & .776 & .000 \\
\hline P2 & .776 & .000 \\
\hline P3 & .782 & .000 \\
\hline P4 & .733 & .000 \\
\hline P5 & .781 & .000 \\
\hline P6 & .782 & .000 \\
\hline P7 & .775 & .000 \\
\hline P8 & .788 & .000
\end{tabular}

\begin{tabular}{cc}
\hline \multicolumn{2}{c}{ Reliability Statistics } \\
\hline Cronbach's Alpha & N of Item \\
\hline $\mathbf{. 7 0 7}$ & 8 \\
\hline
\end{tabular}

Hasil uji validitas kepada 30 responden menunjukkan bahwa seluruh item pertanyaan memiliki nilai $\mathrm{R}$ hitung $>\mathrm{R}$ Tabel, sehingga dapat disimpulkan bahwa seluruh item pertanyaan pada instrumen penelitian telah valid dan dapat digunakan untuk mengukur variabel dalam penelitian ini. Sedangkan hasil uji reliabilitas menghasilkan nilai cronbachs alpha sebesar 0,707 dan telah melebihi 0,6 maka dapat dinyatakan bahwa seluruh instrumen variabel penelitian telah reliabel dan dapat digunakan sebagai instrumen penelitian.

Tabel 6. Pengujian Pemahaman EWS denga angka kecelakaan

\subsection{Analisis Data}

Analisis data dalam penelitian ini terdiri dari analisis data deskriptif dan analisis data statistik dengan analisis korelasi pearson chisqure. Berikut adalah Hasil analisis statistik deskriptif statistik variabel.

Tabel 5. Hasil deskriptif variabel

\begin{tabular}{cccc}
\hline Variabel & Kategori & $\begin{array}{c}\text { Frequ } \\
\text { ency }\end{array}$ & $\begin{array}{c}\text { Percen } \\
\mathbf{t}\end{array}$ \\
\hline Pemahama & Tidak Paham & 86 & 23.9 \\
\cline { 2 - 4 } n EWS & Paham & 274 & 76.1 \\
\hline \multirow{3}{*}{$\begin{array}{c}\text { Melewati Batas } \\
\text { Sinyal EWS }\end{array}$} & 72 & 20.0 \\
\cline { 2 - 4 } $\mathbf{n}$ & $\begin{array}{c}\text { Tidak berhenti } \\
\text { saat lampu merah } \\
\text { menyala dan }\end{array}$ & 288 & 80.0 \\
& $\begin{array}{c}\text { sirine berbunyi } \\
\text { Terjadi }\end{array}$ & 216 & 60.0 \\
\hline \multirow{2}{*}{$\begin{array}{c}\text { Kecelakaa } \\
\text { Kecelakaan }\end{array}$} & $\begin{array}{c}\text { Tidak terjadi } \\
\text { Kecelakaan }\end{array}$ & 144 & 40.0 \\
\cline { 2 - 4 } & & & \\
\hline
\end{tabular}

Hasil analisis menunjukkan bahwa sebanyak 274 atau sebesar $76.1 \%$ memiliki pemahaman terhadap EWS pada perlintasan kereta api sebidang. Pada kategori jenis pelanggaran, sebanyak 288 responden dengan persentase sebesar $80.0 \%$ melakukan pelanggaran dengan tidak berhenti saat lampu merah menyala dan sirine berbunyi. Pada pada kategori kejadian kecelakaan, sebanyak 216 responden dengan persentase sebesar $60.0 \%$ mengalami kecelakaan di perlintasan kereta api sebidang.

Pengujian pearson chisqure tentang Pemahaman EWS dengan Angka Kecelakaan dilakukan secara statistik. Berikut ini hasil pengujian pearson chisquare.

\begin{tabular}{|c|c|c|c|c|c|c|}
\hline & Kece & aan & & & & \\
\hline $\begin{array}{c}\text { Pemahaman } \\
\text { EWS }\end{array}$ & Terjadi Kecelakaan & $\begin{array}{c}\text { Tidak Terjadi } \\
\text { Kecelakaan }\end{array}$ & Total & & Pvalue & $\mathrm{CC}$ \\
\hline $\begin{array}{l}\text { Tidak } \\
\text { Paham }\end{array}$ & 64 & 22 & 86 & \multirow{3}{*}{9.788} & \multirow{3}{*}{0.002} & \multirow{3}{*}{0.163} \\
\hline Paham & 152 & 122 & 274 & & & \\
\hline Total & 216 & 144 & 360 & & & \\
\hline
\end{tabular}


Dari hasil tabel diatas menunjukan bahwa nilai pearson chi square memperoleh hasil sebesar 9.788 dengan signifikansi (pvalue) fisher's exact test sebesar $0.002(0.002<0.05)$, dan hasil korelasi koefesien kontingensi(cc) sebesar 0.163. Sehingga dapat disimpulkan Ho ditolak yang artinya terdapat hubungan yang signifikan dengan hasil korelasi kontingensi pada kategori sangat lemah dan searah antara pemahaman EWS dengan angka kecelakaan di perlintasan sebidang.

Pengujian pearson chisqure tentang Pelanggaran EWS dengan Angka Kecelakaan dilakukan secara statistik. Berikut ini hasil pengujian pearson chisquare.

Tabel 7. Pengujian Pelanggaran EWS denga angka kecelakaan

\begin{tabular}{ccccccc}
\hline & \multicolumn{2}{c}{ Kecelakaan } & & & \\
\cline { 2 - 4 } Pelanggaran & $\begin{array}{c}\text { Terjadi } \\
\text { Kecelakaan }\end{array}$ & $\begin{array}{c}\text { Tidak } \\
\text { Terjadi } \\
\text { Kecelakaan }\end{array}$ & Total & $\mathbf{X}_{\mathbf{2}}$ & Pvalue & CC \\
\hline Melewati Batas EWS & 72 & 0 & 72 & & & \\
\cline { 1 - 4 } $\begin{array}{c}\text { Tidak Berhenti Saat } \\
\text { Lampu Merah Menyala } \\
\text { dan Sirine Berbunyi }\end{array}$ & 144 & 144 & 288 & 60.000 & 0.000 & 0.378 \\
\hline Total & 216 & 144 & 360 & & & \\
\hline
\end{tabular}

Dari Tabel di atas menunjukan bahwa hasil pengujian pearson chisqure tentang pengujian pelanggaran dengan angka kecelakaan memperoleh hasil sebesar 60.000 dengan signifikansi (pvalue) fisher's exact test sebesar $0.000(0.000<0.05)$, dan hasil korelasi koefesien kontingensi(cc) sebesar 0.378 maka Ho ditolak yang artinya terdapat hubungan yang signifikan dengan hasil korelasi kontingensi pada kategori sedang dan searah antara pelanggaran dengan angka kecelakaan di perlintasan sebidang.

\subsection{Hubungan Pemahaman EWS dengan Angka Kecelakaan}

Hasil penelitian mengenai hubungan antara pemahaman EWS dengan angka kecelakaan, memperoleh hasil bahwa pemahaman EWS memiliki hubungan dengan angka kecelakaan. Pengetahuan atau pemahaman merupakan landasan seseorang untuk mengerjakan sesuatu dan berperilaku.

Pengetahuan dapat diperoleh dari pengalaman diri sendiri maupun orang lain yang dapat mempengaruhi/seseorang untuk mempersepsikan sesuatu yang ada terstimulus padanya. Hasil observasi menunjukkan masih banyak pengendara yang berperilaku tidak aman saat mengendarai sepeda motor di saat melalui perlintasan kereta api, hal ini dapat disebabkan karena tingkat pengetahuan yang dimiliki mereka tidak berada pada tingkatan yang paling tinggi dalam hal ini adalah tahap evaluasi dan belum pada tingkatan aplikasi, mengimplemantasikan pengetahuan yang mereka miliki. Tingkat pengetahuan yang dimaksud mengenai lambang, huruf, yang menunjukkan rambu lalu lintas dan peraturan terkait tata cara berkendara. (Notosiswoyo, M, 2014), menyebutkan bahwa perilaku pencegahan terhadap kecelakaan lalu lintas berhubungan dengan pengetahuan yang dimiliki oleh pengguna jalan termasuk pengendara, terkait peraturan lalu lintas. Kejadian kecelakaan lalu lintas dapat disebabkan oleh ada tidaknya implementasi dari pengetahuan yang dimiliki oleh pengendara mengenai segala hal terkait peraturan lalu lintas dan tata cara berkendara. Hal ini terjadi karena adanya perbedaan dan pemahaman terhadap tata tertib berlalu lintas dapat menimbulkan berbagai masalah lalu lintas seperti pelanggaran rambu lalu lintas yang dapat menyebabkan kecelakaan lalu lintas. Setiap pengendara sebagai pengguna jalan memerlukan pengetahuan terkait aspek keselamatan berkendara. Pengetahuan mengenai keselamatan berkendara didapatkan oleh seseorang baik melalui pengalaman pribadi maupun orang lain serta literatur. Pengendara dengan pengalaman yang minim dan kurangnya keterampilan berkendara dengan aman berisiko 
tinggi untuk mengalami kecelakaan dan cedera (Hidayati, Annisa, 2016).

Pada tingkatan mengimplementasikan pemahaman atau pengetahuan pengendara seharusnya telah memiliki kemampuan dalam hal menggunakan pengetahuan atau apa saja yang telah dipelajari (diketahui) untuk diaplikasikan dalam kondisi atau situasi sebenarnya dalam hal ini yaitu diaplikasikan dalam perilaku aman saat berkendara dan mentaati rambu lalu lintas, meskipun demikian pengetahuan yang baik mengenai pemahaman rambu lalu lintas, tidak secara otomatis membuat pengendara melakukan tindakan aman, hal ini terjadi karena beberapa faktor terutama fasiliitas, fasilitas sangat menentukan pemahaman sesorang saat berkendara, yang bila diaplikasikan dapat mencegah terjadinya atau meminimalisir kejadian kecelakaan, khususnya pada perlintasan kereta api

\subsection{Hubungan Pelanggaran dengan Angka Kecelakaan}

Hasil penelitian mengenai hubungan antara pelanggaran dengan angka kecelakaan menunjukan bahwa tingginya jenis pelanggaran yang terjadi yang dilakukan oleh seorang pengendara mengakibatkan tinggi pula angka kecelakaan. Hasil penelitian ini sejalan dengan hasil penelitian (Handayani et al., 2017) yang menyatakan bahwa pelanggaran rambu lalu lintas merupakan salah satu faktor penyebab terjadinya kecelakaan. Pelanggaran yang sering terjadi di lapangan adalah pengendara mengebut karena terburu-buru ingin sampai tempat tujuan dengan mengambil jalur pada arah yang berlawanan sehingga beresiko membahayakan pihak lawan. Pelanggaran terhadap rambu dan lampu lalu lintas juga turut berperan dalam menyebabkan kecelakaan lalu lintas. Hal ini memperlihatkan kurangnya public safety awareness yang dimiliki masyarakat sehingga menyebabkan masyarakat tidak mengutamakan keselamatan dan lebih banyak mengutamakan kecepatan dan faktor ekonomi dalam berlalu lintas (Departemen Perhubungan Privinsi Jawa Barat, 2013). Menurut data dari kepolisian faktor pelanggaran yang dilakukan oleh pengemudi yang kurang tertib berlalu lintas ini mencapai lebih dari $80 \%$ dari penyebab kecelakaan lalu lintas (Kartika, Metta, 2009).

Perilaku berlalu lintas adalah dorongan yang berada dalam diri manusia yang meliputi perjalanan, gerak dari kendaraan tidak secara tibatiba dorongan tersebut dapat hilang pada saat tertentu. Akan tetapi perilaku berlalu lintas tersebut akan tetap ada kelangsungan atau kontinuitas antara satu perbuatan yang kemudian berkelanjutan pada perbuatan berikutnya yang berupa penarikan benda-benda yang dapat bergerak, angkutan penumpang, arus pejalan kaki, dan ditambah dengan beberapa kegiatan yang berhubungan penggunaan jalan umum. Aspekaspek perilaku berlalu lintas yang banyak mengakibatkan kecelakaan yaitu pelanggaran rambu-rambu lalu lintas dan perilaku mengendarai sepeda motor (Alyandi, 2018). Errors dapat dilihat sebagai suatu konsekuensi dari pada penyebab (Reason, 2000), tindakan tidak aman seperti memacu kendaraan diatas batas aman (kecepatan > $40 \mathrm{~km} / \mathrm{jam}$ ) berhubungan dengan banyak terjadi kecelakaan di Indonesia (Sulistio,H, 2018). Faktor sosial, sosial ekonomi, gaya hidup, budaya, gaya dan keterampilan mengemudi secara umum berpengaruh terhadap kebiasaan pelanggaran mengemudi yang dilakukan pengemudi (Bener,dkk, 2016). Investigasi pelanggaran pengendara, menunjukkan pelanggaran dominan adalah pengendara melaju dengan kecepatan melebihi batas maksimal (Kashani,dkk, 2016).

\section{KESIMPULAN DAN SARAN}

Berdasarkan hasil penelitian mengenai maka diperoleh kesimpulan sebagai berikut :

1) Pemahaman EWS memiliki hubungan yang sangat lemah dan searah dengan angka kecelakaan di perlintasan sebidang. Hal ini menujukan bahwa semakin tinggi tingkat pemahaman EWS seorang pengendara, maka akan menekan atau menimalisir jumlah kecelakaan yang terjadi kecelakaan di perlintasan sebidang yang memiliki EWS.

2) Jumlah pelanggaran memiliki hubungan yang sedang dan searah dengan angka kecelakaan di perlintasan sebidang. Hal ini menujukan bahwa semakin tinggi jumlah pelanggaran, maka akan semakin meningkatkan jumlah 
kecelakaan yang terjadi di perlintasan EWS tersebut.

\section{REFERENSI}

[1] Ary Putra Iswanto \& Willy Artha Wirawan. (2020).Community Characteristics in the Use of the Madiun-Surabaya Railway and Bus Transportation Mode. Vol 4 No 1 (2020): Jurnal Perkeretaapian Indonesia Volume 4 Nomer $1 \quad$ Tahun 2020. DOI: https://doi.org/10.37367/jpi.v4i1.108.

[2] Handayani, D., Ophelia, R. O., Hartono, W., \& Maret, U. S. (2017). Pengaruh pelanggaran lalu lintas terhadap potensi kecelakaan pada remaja pengendara sepeda motor. E-Jurnal Matrks Teknik Sipil, September, 838-843.

[3] Ghozali,Imam(2016). Aplikasi Analisis Multivariate dengan Program IBM SPSS 25(Edisi 9).Semarang:Universitas Diponegoro

[4] Bener,dkk2016The Driver Behaviour Questionnaire as an Accident Predictor in Cross-cultural Countries in Qatar and Turkey : Global Public Health ProblemBritish Journal of Medicine \& Medical ResearchVol.15 No.7

[5] Driver Traning: A Perceptual Motor Skill Approach 1982 Ergonomic25,917-924

[6] Guoqiang Cai 2020 System Architecture Of a Train Center Network for Automatic Train Safety Monitoring State Key Lab Of Rail Train Control \& SafetyJournal Computers \& Industrial Engineering Vol. 4 No. 2

[7] Hidayati, Annisa 2016 Analisis Risiko Kecelakaan Lalu Lintas Berdasar Pengetahuan, Penggunaan Jalur dan Kecepatan BerkendaraJurnal Berkala Epidemiologi275-287

[8] Hubungan Pendidikan di dalam Keluarga Terhadap Perilaku Pengemudi Kendaraan Bermotor Saat Berlalu Lintas 2018 Jurnal Mitra Teknik Sipil48-54

[9] Juneman,(2010). Masalah Transportasi Kota dan Pendekatan Psikologi Sosial Psikobuana.Vol. 1, No.3, 173-189

[10] Kartika, Metta, 2009, Analisis Faktor Penyebab Kecelakaan Lalu Lintas Pada
Pengendara Sepeda Motor di Wilayah Depok DepokUniversitas Indonesia

[11] Kashani,dkk.(2016). Analysis of Drivers' Behavior using Manchester Driver Behavior Questionnaire Based on Roadside Interview in IranInternational journal of transportation Engineering

[12] Mohan, dkk.(2006). Road Traffic Injury Prevention : Training Manual. India : WHO

[13] Notosiswoyo, M2014Pengetahuan, Sikap,dan Perilaku Siswa SLTA dalam Pencegahan Kecelakaan Sepeda Motor di Kota Bekasi.Jurnal Ekologi KesehatanVol. 13 No. 1

[14] Nanda Ahda Imron., et.al. (2018). Application of Automatic Level Crossing Technology in Indonesia. Vol. 2. No 2. Tahun 2018. DOI: https://doi.org/10.37367/jpi.v2i2.55

[15] Omy,(2019). 4 Faktor Penyebab Kecelakaan di Perlintasan Sebidang. Kendal:Berita Trans

[16] Satri,(2006). Sistem Informasi Peringatan Dini.Jakarta: Gramedia

[17] Sugiyono,(2016:39).Metode Penelitian Kuantitatif, Kualitatif $R \& D$ BandungPT. Alfabet

[18] Sulistio,H2018Effect of Traffic Flow, Proportion of Motorcycle, Speed , Lane Width , and the Availabilities of Median and Shoulder on Motorcycle Accidents at Urban Roads in Indonesia.The Open Transportation Jurnalpp 1-7

[19] Wardana, D.H,(2004). Studi Kemacetan Lalu Lintas JL. Letjen Soeprapto. FSTPT International Symposium 